\title{
UM ESTUDO DAS INTERAÇÕES DOS JOVENS EM ESPAÇOS VIRTUAIS
}

\section{RUTINELLI DA PENHA FÁVERO}

Instituto Federal do Espírito Santo (IFES)

E-mail: rutinelli@ifes.edu.br

\section{SONIA CRIStina SOARES Dias Vermelho}

Universidade Federal do Rio de Janeiro (UFRJ)

E-mail: cristina.vermelho@gmail.com

\section{ANA AMÉlIA AMORIM CARVALHO}

Universidade de Coimbra (UC)

E-mail: anaameliac@fpce.uc.pt

\section{RESUMO}

Buscou-se refletir sobre os processos de interação mediada por tecnologias tendo como guia do percurso as seguintes questões: em que consiste a interação mediada pelas tecnologias digitais? Quais são os elementos distintivos da interação em espaços virtuais? Utilizando como delineamento da pesquisa a netnografia com observação participante, foi realizado um estudo das postagens e interações de jovens na rede social Instagram. Como resultado percebeu-se que as interações são sempre uma relação dialética entre o social e o individual. Além disso, o horizonte extraverbal faz-se essencial para o sucesso das interações. Portanto, deve-se buscar compreender o quanto isso impacta as ações de educação que perpassam a interação mediada por tecnologias.

\section{PALAVRAS-CHAVE:}

Interação; TIC; Redes-sociais; Comunicação.

\section{ABSTRACT}

We sought to reflect on the processes of interaction mediated by technologies with the following questions as a guide in the course: what does the interaction mediated by digital technologies consist of? What are the distinguishing elements of interaction in virtual spaces? Using netnography with participant observation as a research design, a study was carried out on the posts and interactions of young people on the social network Instagram. As a result, it was noticed that interactions are always a dialectical relationship between the social and the individual. In addition, the extraverbal horizon is essential for the success of interactions. Therefore, one must seek to understand how much this impacts on education actions that pervades the interaction mediated by technologies.

\section{KEYWORDS:}

Interaction; ICT; Social Media; Communication.

\section{INTRODUÇÃO}


Desde os anos 40, no pós-guerra, com a criação de máquinas que poderiam armazenar informações, até à primeira rede que ligava computadores no departamento de defesa dos Estado Unidos da América para fins militares, do primeiro e-mail ao contínuo crescimento no uso da internet (COSTA DO VALE; COSTA, ALVES, 2001), os processos comunicacionais foram ampliados pelas possibilidades que as tecnologias trouxeram. Ainda que a acessibilidade de uso da Internet, dos computadores e dos smartphones dependa, também, de questões econômicas e, por isso, não foi, nem é, igualitariamente distribuída, ela hoje é utilizada por todas as classes sociais em números que refletem a importância e permanência das formas de comunicação mediada e das práticas culturais que as TIC tem alcançado. Se em 2005, no Brasil, 13\% dos domicílios possuíam acesso à Internet, em 2018 eram 67\%. Caso desloquemos o olhar para os resultados das pesquisas sobre os indivíduos, 70\% dos respondentes haviam acessado a internet nos últimos 03 (três) meses de quando foram abordados (Comitê Gestor da Internet no Brasil, por meio do Núcleo de Informação e Comunicação do Ponto Br (CETIC.BR, 200; CETIC.BR, 2018).

Em 2020, vimos os processos comunicacionais mediados por tecnologias atingirem picos de destaque. Além dos processos socioeconômicos que trouxeram a criação das tecnologias digitais e a propagação dos usos da Web, uma outra questão que amplificou e, de certa maneira, modificou os processos comunicacionais, tensionando muito a interação online, foi a pandemia da COVID-19 e as ações políticas, econômicas e sociais advindas desse contexto.

A forma pela qual as pessoas passaram por este período relacionou-se com o alcance, ou não, do mínimo necessário para a sobrevivência. No Brasil, as desigualdades sociais produziram desigualdades na forma de viver a pandemia. Muitos trabalhadores correram riscos, pois não puderam trabalhar de suas casas e foram postos em perigo para que o consumo continuasse (HARVEY, 2020). 
Sobre as instituições escolares, depois de março de 2020, houve o encerramento do ensino presencial em todos os níveis. Assim, ocorreu de muitas maneiras, uma busca pela continuidade nas atividades, de modo remoto. Houve uma diversidade de condições que afetaram alunos e professores, nomeadamente: o acesso material às redes wifi, a estrutura do lar em abrigar o processo educativo, o contato anterior com o ensino a distância ou híbrido, o conhecimento dos usos das TIC em educação, entre outros possíveis. A busca por uma condição mínima de acesso à estrutura para o ensino remoto passou a constar da luta da educação popular.

Para além da escola, os jovens são os usuários mais frequentes das redes sociais e das novidades on-line, "[...] Os sites de redes sociais digitais, os jogos on-line, os sites de compartilhamento de vídeo, os gadgets e os smartphones são agora os acessórios da cultura e, mais especialmente, dos jovens" (PORTO et al., 2017, p.10). É necessário compreender mais profundamente os usos das redes e a construção cultural das relações estabelecidas nas conexões virtuais, pois são palco e produto das ações dos jovens, assim como as interações nestes locais acontecem e impactam a sociedade, incluindo-se os aspectos educacionais. Nessa investigação, desenvolvemos uma reflexão sobre o processo de interação mediada pelas tecnologias digitais. As questões que, inicialmente, emergem são: Em que consiste a interação mediada pelas tecnologias digitais? Quais são os elementos distintivos da interação em espaços virtuais?

Procurando compreender melhor essas questões, foi realizado um estudo com jovens entre os 13 e os 17 anos, a partir de suas postagens em uma rede social. A escolha por esse público se justifica pelo fato de ser uma faixa etária foco de políticas educacionais de base e, também, pela quantidade e formas de acesso à virtualidade desses jovens (CETIC.BR, 2018). A rede social definida para este estudo é o Instagram, cenário metodológico escolhido pelas possibilidades diferentes de interação e por ser usado pela faixa etária alvo. 
O trabalho segue um percurso definido como uma possibilidade de pontos dentro de um cenário de links, de tal forma que ele não encerra nas linhas descritas a realidade das práticas de interação, nem mesmo a isso se propõe, mas entende que a realidade deve ser narrada por diversos trajetos e vivências que juntos captam as contradições, os avanços e possibilitam compreensões não observadas.

\section{JUVENTUDES E AS INTERAÇÕES MEDIADAS POR TECNOLOGIAS}

Dentro da perspectiva jurídica brasileira, Lei no 12.852 (BRASIL, 2013), é jovem quem está na faixa entre 15 e 29 anos $^{1}$. Ao analisarmos dados de 10 anos da pesquisa Agenda Juventude Brasil, Abramo (2016) caracteriza como uma das formas de entender o período de juventude, aquele em que se processa o ingresso no mundo do trabalho (mesmo que não seja regra).

Marcar o início da juventude incorpora, além da entrada no mundo de trabalho, outras características na sociedade brasileira: o processo de deixar de ser apenas filho para o de ser responsável pela família ou o único responsável; o processo de escolarização ou, pelo menos, a parte "obrigatória" dos níveis educacionais; as marcas de desenvolvimento corporal; as muitas maneiras de amar e de viver os afetos e a sexualidade e as formas de engajamento social e lazer que mostram meios de ser e as possibilidades de estar na concretude do mundo.

Esses aspectos indicam que o 'juvenir' pode ser um período específico de idade entre a infância e a maturidade. Porém, ser específico não quer dizer ser linear ou unicamente crescente. Com a complexidade social, esses processos também se intensificam e ampliam, de modo que formas diferentes de ser jovem coexistem, momentos nos quais se está em um ou outro ponto do processo e de muitas formas.

\footnotetext{
${ }^{1}$ Entre 15 (quinze) e 18 (dezoito) anos, na faixa de juventude entendido como adolescência, aplica-se a Lei no 8.069, de 13 de julho de 1990 - Estatuto da Criança e do Adolescente juntamente com o Estatuto da Juventude, desde que não haja conflito. 
Nas palavras de Abramo $(2016$, p.16) [...] A singularidade da condição juvenil é dada pelo que se vive nesse momento da vida, numa dada conjuntura histórica [...].

Se em alguns momentos, o juvenir é estendido pelas pressões diversas, de forma semelhante, o desjuvenecer é adiantado ou mesmo quase encontrado na infância. As entradas e saídas do mundo do trabalho e do mundo da escola formal são tanto parte desses processos quanto termômetros dele (NOVAES, 2016).

Uma importante marca da diversidade de modos de iniciar e estar na juventude é a construção de identidades sociais que caminham da individualização para a integração, a partir da socialização iniciada ao longo da infância, em processos constituintes que mudam e são modificados constantemente (VYGOTSKY, 1988; CIAMPA, 1987). Esses processos de identidades, desenvolvidos pela internalização de conceitos, a partir da linguagem, são materiais e imateriais, pois além das experiências dos indivíduos reais, também são produções teóricas com as marcas das práticas realizadas em uma sociedade (VYGOTSKY, 1988). Enquanto processos de identidade demonstrados para fora de si, a partir da vivência de muitos papéis (CIAMPA, 1987), mantêm-se relacionados às condições de vida as quais o jovem experiencia. Apesar da totalidade de vida do sujeito, ele se relaciona com o outro na construção de identidades fluidas e, por isso, históricas, como explicita Bauman (2008, p.102):

[...] Todos nós, em maior ou menor grau, entendemos o mundo em que habitamos como cheio de riscos, incerto e inseguro. Nossa posição social, nossos empregos, o valor de mercado de nossas habilidades, nossas parcerias, vizinhanças e redes de amigos em que podemos nos apoiar são todas instáveis e vulneráveis - portos inseguros para ancorar nossa confiança. A vida de constante escolha do consumidor também não é tranqüila: o que dizer da ansiedade perpétua no que diz respeito à sensatez das escolhas que temos de fazer todos os dias; e da identidade que todos buscamos desesperadamente, com seu detestável hábito de sair de moda bem antes que a descubramos?

As identidades que são construídas ou apresentadas socialmente, pela sua relação com as condições materiais de vida, são diferentes nas variadas sociedades. 
Uma sociedade marcada pela desigualdade, como a brasileira, apresenta nas oportunidades de construção de identidades indícios advindos dessa desigualdade, com diferenças latentes em relação à juventude de países desenvolvidos. Além disso, a força da desigualdade de uma sociedade que vê as identidades juvenis como mercado de uma cultura de consumo busca, por meio das tecnologias, uma forma nova de abarcar e emaranhar as possibilidades de tudo que é produzido (BAUMAN, 2013), inclusive as produções identitárias "[...] Com a juventude em cena suas memórias e suas identidades foram tatuadas no corpo, posto que as práticas sociais são externadas corporalmente e aí têm suas marcas perpetuadas" (DANTAS JUNIOR, 2007, p. 65)

A possibilidade de conexão, dialeticamente refletida como possível emancipação e exclusão, é uma realidade entre os jovens brasileiros.

[...] os jovens atingem a idade da busca pela autonomia, mas na cultura digital eles fazem isso por maneiras diferentes, com outros modos de comunicação, outras formas de se relacionar, novas formas de jogar, novas formas de expressão e também de exposição (PORTO et al., 2017, p.10)

Sposito (2002) indicava que as teses e dissertações sobre o público jovem e o papel da mídia apontava a televisão como o veículo de maior interesse, hoje não é mais possível considerar a temática sem reconhecer que as TIC contribuem para uma outra forma de ser e de se colocar no mundo e isso impacta as formas de juvenir. Não é possível se debruçar sobre a temática da juventude e ignorar as TIC. "[...] esta é a primeira geração em que - a despeito das persistentes desigualdades sociais - a internet chega aos jovens que não terminaram o ensino fundamental" (NOVAES, 2016, p. 235).

Além do fato de os jovens poderem usar as TIC muito mais do que as gerações anteriores, são as experiências que eles possuem a partir das Tecnologias da Informação e da Comunicação que interessam, tais como suas visões, reflexões, humores e a relação disso tudo com suas maneiras de viver. Para Benjamin (1986), na 
reflexão acerca da instituição escolar, o caminho do jovem, integrado aos seus muros, não é mais importante do que as experiências oferecidas nos currículos, ou fora dos muros. Assim também, as tecnologias, mesmo com o potencial excludente, possuem características de amplificação das relações e, com isso, das experiências na criação da vida das pessoas. É preciso viver a experiência para ser modificado por ela e, para Benjamin (1986), a experiência do/com o conhecimento precisaria ser total e profunda.

Para Marcuse (1975), a juventude possui a necessidade biológica de mudança, a juventude com seu Eros luta contra a força de Tanatos na repressão, para o encaixe total do humano nos aspectos opressivos dessa civilização. Enquanto sociedade organizada a partir de um princípio repressor, tudo dela produzido segue esse princípio, inclusive a organização do trabalho, que reforça a repressão (MARCUSE, 1975). Da mesma forma que a organização do trabalho, a organização dos modos de produção e utilização das TIC também emergem nos princípios reprodutores da repressão para a configuração da norma social. Mas, existe também um princípio anárquico, nem sempre para vida.

Tomando como base as palavras de Marcuse (1975), a não-repressão modificaria as relações e a libertação de Eros faria diferença na organização de outras formas de relação com o trabalho e, por consequência, com a potência da própria vida. A relação entre juventude e tecnologia, então, pode conter pistas das potencialidades deste processo.

Um local de práticas dessa relação dialética entre a identidade e a sociabilidade são as redes sociais, as quais são locais de ações da individualidade constantemente reforçada pelos likes, comentários e ações da coletividade.

Ao utilizar as redes sociais, os jovens buscam o espaço público de uma tela, na qual são expostos dramas, humores, ideias e preocupações dos indivíduos (BAUMAN, 
2008). Esse reforço da individualidade acontece, paradoxalmente, a partir das interações possíveis nos ambientes virtuais. O reforço da individualidade na tela precisa das possibilidades da interatividade social.

Em certo sentido, uma rede social é um local análogo às ações presenciais na quais as pessoas são ligadas por laços sociais (RECUERO, 2009), porém, nela, pode haver, ou não, contato físico. A evolução dos usos das redes sociais mostrou que o real e o virtual não são antônimos, são ligações de uma mesma vida, sendo que, se o virtual pode ser entendido como aquilo que existe em potencial (LEVY, 1996), hoje, ambos existem em potencial e, em certo sentido, também em material.

Quanto às interações nas redes sociais, elas baseiam-se em um sistema simbólico que permite o estabelecimento da comunicação (OLIVEIRA, 1992). Este sistema possui conexões que se misturam em diversas ramificações: parte da compreensão do código escrito em determinada língua; de imagens, emojis, memes etc; parte, ainda, de certa compreensão do funcionamento da própria plataforma onde a interação se estabelece. São processos sistêmicos que permitem a interação. Mas, não são os únicos processos envolvidos.

A natureza composta das relações, além daquilo que está postado, é caracterizada não apenas pelo discurso verbal, mas por todo um horizonte extraverbal que traz, em si, a compreensão do mundo da vida concreta, ampla e pragmática dos que estão interagindo (VOLOSHINOV \& BAKHTIN, 1976). Essa natureza faz com que a interação virtual possua graus de enredamento e, em algum sentido, as interações virtuais lançam mão de artifícios para a compreensão desse horizonte extraverbal, já que o discurso verbal sozinho, mediado pelas tecnologias, pode não dar conta de explicitar e significar seu conteúdo.

A interação é objeto de atenção na área de educação, em especial, na educação a distância (MOORE \& KEARSLEY, 2007). Entre os estudos de interação em EAD 
destacam-se os de Moore (2002) que construiu uma teoria muito utilizada no desenho de cursos a distância, na qual é discutida a interação à distância, compreendendo que as distâncias geográficas são diminuídas pelos avanços das tecnologias educacionais.

Ainda que esta teoria seja especificamente relacionada com a educação a distância, especialmente com os níveis ou variáveis que afetam a distância na interação, ela é importante para compreensão das interações em todos os ambientes virtuais. Entre as variáveis trazidas por ela, citamos brevemente: necessidade de diálogo - ou seja, interações bem-sucedidas e constantes; o impacto da estrutura para a interação - seja o projeto do curso ou seja do ambiente de rede social; e a autonomia do aluno - "[...] quanto maior a estrutura e menor o diálogo em um programa, maior autonomia o aluno terá de exercer" (MOORE, 2002, p. 06). Dentro de plataformas como o Instagram, a estrutura do ambiente permite amplas e diferentes interações, com diálogos muito distintos das intenções de interações em Ambientes Virtuais de Aprendizagem, ainda assim, as questões relacionadas à teoria de Moore, mesmo que não para o objetivo de aprendizagem, são importantes na reflexão do quanto de autonomia se exerce frente ao conteúdo das interações em ambientes mais livres do que o de um curso em educação formal, tal como os das redes sociais.

O avanço das relações possíveis com as interfaces e dos softwares que medeiam as interações faz-nos atentar para a interação com a tecnologia em si (HILLMAN et al., 1994). Este foco, porém, é simultâneo e subordinado às relações entre os sujeitos, naquilo que produzem no contexto de suas relações (PRIMO, 2003). Mesmo que sejam, necessariamente, observados pontos dos sujeitos, pontos das interfaces e pontos do conteúdo, a interação que, aqui, tem ênfase, somente, pode ser compreendida na complexidade dos seus pontos e links, ou seja, na junção dessas variáveis. 
Tal como Primo (2003), nos interessa, compreender as interações mediadas pelas TIC, na ação entre as pessoas, porém, pela característica das interações mediadas, pelo crescente papel dos softwares e da Inteligência Artificial (IA), influenciando diretamente em quê e como que as pessoas interagem, não estabeleceremos divisões, tal como, por exemplo, a divisão entre interação reativa - a qual toda troca é condicionada ao estímulo; e interação mútua - na qual há uma liberdade de escolha e respostas, ainda que as interações possam ser estudadas desta maneira, ou, ainda, possam ser compreendidas como híbridas, com características mútuas e reativas. Parece-nos que as interações mediadas pelas TIC, em especial nas redes sociais por suas características como locais de laços sociais, ampliam as possíveis respostas em modos e formas, mesmo que sejam condicionadas por um local, um modo e, às vezes, uma ação algorítmica, que indicam quem interage com qual conteúdo e, consequentemente, com qual pessoa. Ampliam em modos porque permitem mídias e ações diversas para postagens e para respostas; e ampliam em formas, porque as diversas pessoas que respondem a um determinado estímulo fazem com que ele seja mais complexo do que apenas uma determinada fala isolada.

Em face disso, a interatividade no atual contexto histórico pode ser assim conceituada, conforme Lemos (1997, p. 03):

[...] uma nova forma de interação técnica, de cunho "eletrônico-digital", diferente da interação "analógica" que caracterizou os média tradicionais. Podemos compreender a interatividade digital como um diálogo entre homens e máquinas (baseadas no princípio da microeletrônica), através de uma "zona de contato" chamada de "interfaces gráficas", em tempo real. A tecnologia digital, possibilita ao usuário interagir, não mais apenas com o objeto (a máquina ou a ferramenta), mas com a informação, isto é, com o"conteúdo".

Assumindo, aqui, os limites de proximidade entre os conceitos de interação e interatividade, compreendemos que o processo histórico das tecnologias e das interações está contido, dialeticamente, na história da própria humanidade, por abarcar as relações sociais fundamentais aos homens e mulheres em suas relações 
entre si e com a natureza. Assim, é certo que as interações não foram inventadas pelos processos binários do computador, mas ela foi sendo modificada, e modificou as relações humanas, de modo que, por ora, estabeleceu-se uma relação própria nas formas virtuais.

A interação - seja em suas formas tradicionais, seja pelas possibilidades relacionadas com as tecnologias - pode se apresentar de maneiras diferentes em locus diferentes. As diversas relações estabelecidas em locais virtuais, mediadas primeiramente pelos múltiplos gadgets, possibilitam formas diferentes de interação que poderemos chamar, também, de interatividade.

A interatividade, no sentido mais restrito, pode ser utilizada para referir-se às formas como as pessoas agem sobre os conteúdos que recebem ou constroem e suas aplicações, inferindo sobre eles de algum modo, ou seja, a partir de ação e controle. Vista assim, quanto maior a ação sobre o conteúdo, maiores possibilidades de aprendizagem, por exemplo. Para fins deste trabalho, porém a interatividade será entendida aqui como maior do que inferência e controle (SIMS, 1995).

Outra forma de entender a interatividade diz respeito à comunicação entre mídia de massa e público, culminando, na produção de conteúdo. A comunicação permitida por meio de plataformas tais como Twitter, Instagram e Youtube fornecem meios para que essa interatividade aconteça (PERNISA JÚNIOR, 2010). Porém, a interatividade será tratada como uma ampliação dessa visão, para além da simples produção de uma notícia, verdadeira ou falsa, ou do consumo dessa informação, ainda que em tempo real.

Neste artigo, iremos priorizar o conceito de interação, concordando com Anderson (2003), ainda que ele esteja se referindo à EAD, a interação é, em certo modo, a quantidade de vezes na qual as pessoas se comunicam de forma engajada. Embora possa existir algum grau de interação na medida em que as pessoas observem 
as interações de outras pessoas, isso não é de fácil análise e não se estabelece de forma satisfatória por não haver o 'entre' da relação de interação. É o que acontece com os status do Instagram, ainda que possa haver interação, por não ficar público, não permite a diversidade da interação que as postagens permitem.

\section{METOdOLOGIA}

Neste trabalho, usamos a netnografia, priorizando o procedimento da observação participante, como linha de aproximação e aprofundamento da realidade, a partir do contexto social e histórico, necessário a ser descrito e compreendido, por meio da relação da práxis e da concretude de vida dos jovens participantes.

[...] A netnografia é pesquisa observacional participante baseada em trabalho de campo online. Ela usa comunicações mediadas por computador como fonte de dados para chegar à compreensão e a representação etnográfica de um fenômeno cultural ou comunal (KOZINETS, 2014, pp. 61-62).

Buscamos na netnografia essa possibilidade de tornar-se orgânica, de tal forma que permita acompanhar, utilizando como base a observação participante das interações on-line, além disso, a flexibilidade do seu uso favorece abarcar as mídias que existem nas redes sociais mais usadas.

Dentro destas perspectivas, com base em Bauer (2002); Esteban (2010); Horkheimer (1983) e Kozinets (2014), descrevemos o caminho utilizado neste trabalho: definição da rede social Instagram como cenário da pesquisa; descrição dos cenários e das suas potencialidades de interação; acompanhamento das interações na rede social; produção e aplicação de uma base escalar para fins de compreensão dos graus de profundidade das interações; análise das interações a partir da base teórica, dando, ainda, ênfase aos pontos de interação/interatividade.

Para fins de recrutamento, foi realizada uma ação para visibilidade da pesquisa na qual foram disponibilizados dados sobre o projeto e um contato de rede social criado especialmente para que os jovens viessem a conhecer a proposta. Essa ação 
aconteceu de dezembro de 2019 a agosto de 2020. Ao longo desse período os jovens interessados foram selecionados a partir da livre adesão e enviaram o Termo de Assentimento Livre e Esclarecido (TALE) e o Termo de Consentimento Livre e Esclarecido (TCLE) assinados por si e pelos seus responsáveis. Este trabalho foi anteriormente avaliado pelo Comitê de Ética em Pesquisa do Ifes (Parecer 3.739.709).

A amostra foi composta no total de 06 (seis) jovens, participantes por livre adesão, com paridade de gênero. As publicações analisadas constavam de um recorte temporal de 06 (seis) meses, buscando, com isso, certo aprofundamento das questões de pesquisa. Foi escolhido o Instagram, como cenário metodológico, pelas possibilidades diferentes de interação e por ser usado pela faixa etária alvo.

O Instagram tem um formato que, no momento, é uma das mais comuns de redes sociais, permite a construção de um perfil que pode ser ou não público e esperase que os usuários criem conexões com outros usuários do mesmo site e que visualizem as suas conexões dentro do sistema, a partir das postagens realizadas por todos (MCINTYRE, 2014).

Ele foi criado em 2010 a partir de um aplicativo chamado Burbn. O primeiro atrativo do Instagram eram os filtros que possibilitavam mudar e melhorar as imagens de fotografias. Hoje, além da postagem de fotos e vídeos (inclusive vinculado ao novo app Tik Tok) na linha do tempo, os comentários também são no estilo fórum, que permitem aos usuários a interação, sempre a partir dessas imagens, podendo ser utilizadas também hashtags e emojis. Em 2016, uma nova forma de interação, a partir do sucesso de aplicativos similares, trouxe ao Instagram o Stories, uma forma ainda mais fluida de compartilhar imagens e vídeos, pois eles desaparecem para os seguidores em 24 horas. Existe também a função de vídeos ao vivo, lives, e de conversas particulares no direct (CARDOSO, 2018). 
Como indicado, são objetos de atenção às interações no Instagram, mais precisamente as postagens de mídias, os comentários e as relações estabelecidas entre os usuários nas linhas do tempo².

Para fins de descrição e análise, podemos dividir em 3 (três) fases o tempo de pesquisa e de observação dos perfis: Fase de reconhecimento, Fase de acompanhamento e Fase de análise. Na Fase de reconhecimento, foram realizadas as seguintes etapas: criação de um perfil no Instagram para acompanhamento dos perfis dos jovens, postagem inicial no perfil criado, busca pelos participantes, contato, explicação dos objetivos e metodologia da pesquisa, assinatura do TCLE, criação de um diário de campo para registro de todas as interações e ações de pesquisa e visualização dos perfis.

A Fase de acompanhamento teve como ações principais a validação e ajustes na planilha de análise, realizadas a partir da visualização dos perfis dos jovens com suas interações e do referencial teórico. A planilha foi construída, em sua primeira versão, com três aspectos priorizados acerca das interações: planejamento, propriedades interativas e comunicação. Na parte de planejamento, buscava-se responder do que foi feito. No item de propriedade interativas, procurava-se a compreensão de como a postagem foi feita em termos de certa preocupação com a qualidade do que ia ser postado. Já a comunicação, referia-se ao retorno, à interação em si.

Neste momento da pesquisa, percebemos o impacto da pandemia, também nas interações on-line. Por causa da necessidade de isolamento social, os jovens não saíram ou saíram menos, não encontraram os amigos e não postaram muitas imagens. Alguns, migraram para mais postagens em stories. Então, se por um lado foi um momento de intensificação do contato virtual, por outro, houve mudança na forma pela qual as pessoas interagiam.

\footnotetext{
${ }^{2}$ Não foram acessadas informações referentes aos chats pessoais.
} 
Após alguns meses de acompanhamento das interações, foram realizados ajustes nos pontos de análise, gerando uma nova planilha. Nesta versão final, 04 (quatro) aspectos foram priorizados: Organização/Planejamento, Propriedades Operacionais, Comunicação e Dimensão Afetiva. Estes itens são parte do que buscamos apreender tendo em vista os estudos de Argyle, (1976); Vygotsky (1988, 2001) e Voloshinov e Bakhtin (1976), entendendo que os processos de interação são impactados por questões concretas, pelos modos de vida das pessoas, pela relação cultural a partir da interiorização da linguagem e pelas competências e habilidades pessoais individuais.

No Quadro 1 apresentamos essas relações de maneira separada para destaque, porém, é importante ressaltar que todas elas juntas, sobrepostas e interpostas fazem parte do processo interativo e se relacionam em todo o tempo.

Quadro 1: Aspectos de impacto para a interação on-line. Fonte: Autoria da pesquisa.

\begin{tabular}{|c|c|c|c|}
\hline Classificação & \multicolumn{2}{|c|}{ Descrição } & Pontuação \\
\hline \multirow{4}{*}{$\begin{array}{l}\text { Planejamento e } \\
\text { Organização das } \\
\text { Publicações }\end{array}$} & O que foi feito? & $\begin{array}{l}\text { Postagem, storie, } \\
\text { comentário, visualização }\end{array}$ & \multirow{4}{*}{$\begin{array}{l}\text { Alto nível de } \\
\text { planejamento - } \\
5 \\
\text { Baixo nível de } \\
\text { planejamento - } \\
1\end{array}$} \\
\hline & $\begin{array}{l}\text { Quantidade de ações } \\
\text { prévias }\end{array}$ & $\begin{array}{l}\text { O quanto foi necessário de } \\
\text { dedicação anterior para } \\
\text { realizar a postagem? }\end{array}$ & \\
\hline & $\begin{array}{l}\text { Tempo gasto } \\
\text { previamente }\end{array}$ & $\begin{array}{l}\text { Quanto tempo anterior foi } \\
\text { gasto para realização da } \\
\text { postagem? }\end{array}$ & \\
\hline & $\begin{array}{l}\text { Compreensão do } \\
\text { preparo da postagem }\end{array}$ & $\begin{array}{l}\text { Como a postagem foi } \\
\text { pensada: dia, horário, } \\
\text { indicação etc? }\end{array}$ & \\
\hline \multirow[t]{2}{*}{$\begin{array}{l}\text { Propriedades } \\
\text { operacionais }\end{array}$} & $\begin{array}{l}\text { Características das } \\
\text { imagens }\end{array}$ & $\begin{array}{l}\text { Qual imagem, o que } \\
\text { aparece, cores, pessoas, } \\
\text { coisas, gifs, memes, emojis, } \\
\text { etc? }\end{array}$ & \multirow{2}{*}{$\begin{array}{l}\text { Alto nível de } \\
\text { propriedades } \\
\text { operacionais - } 5 \\
\text { Baixo nível de } \\
\text { propriedades } \\
\text { operacionais - } 1\end{array}$} \\
\hline & $\begin{array}{l}\text { Características dos } \\
\text { áudios }\end{array}$ & $\begin{array}{l}\text { Como é o som, tem música, } \\
\text { ambiente, voz, entonação, } \\
\text { altura, timbre etc? }\end{array}$ & \\
\hline
\end{tabular}




\begin{tabular}{|c|c|c|c|}
\hline 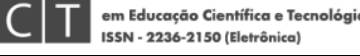 & \multicolumn{3}{|c|}{ Revista Eletrônica DECT, Vitória (ES), v. 10, edição especial dinter, p. 212-239, 2020} \\
\hline & $\begin{array}{l}\text { Características dos } \\
\text { vídeos }\end{array}$ & $\begin{array}{l}\text { Quais são as imagens e os } \\
\text { sons combinados? }\end{array}$ & \\
\hline & $\begin{array}{l}\text { Característica dos } \\
\text { textos }\end{array}$ & $\begin{array}{l}\text { O texto está na imagem ou } \\
\text { na legenda, é longo, tem } \\
\text { emojis, outras } \\
\text { características? }\end{array}$ & \\
\hline & Houve visualização & $\begin{array}{l}\text { Quantidade, percentual, } \\
\text { comparativo }\end{array}$ & \\
\hline & $\begin{array}{l}\text { A postagem é em } \\
\text { tempo real }\end{array}$ & $\begin{array}{l}\text { Se for uma live, como ela se } \\
\text { apresenta? Existe } \\
\text { intencionalidade de } \\
\text { interação dupla em tempo } \\
\text { real ou apenas a postagem } \\
\text { de um vídeo? }\end{array}$ & \\
\hline Comunicação & $\begin{array}{l}\text { Como os seguidores } \\
\text { responderam }\end{array}$ & $\begin{array}{l}\text { Houve comentário, como } \\
\text { eles são, quais as formas, } \\
\text { aconteceu retorno, quais } \\
\text { sinais? }\end{array}$ & $\begin{array}{l}\text { Alto nível de } \\
\text { comunicação - } 5 \\
\text { Baixo nível de } \\
\text { comunicação - } 1\end{array}$ \\
\hline Dimensão Afetiva & $\begin{array}{l}\text { Como o aspecto } \\
\text { subjetivo relacionado } \\
\text { com sentimentos } \\
\text { aparece nas } \\
\quad \text { postagens }\end{array}$ & $\begin{array}{l}\text { Qual o prazer ou desprazer } \\
\text { com a postagem? }\end{array}$ & $\begin{array}{l}\text { Alto nível } \\
\text { afetivo - } 5 \\
\text { Baixo nível } \\
\text { afetivo - } 1\end{array}$ \\
\hline
\end{tabular}

Para fazer a análise das interações, englobando essa múltipla e complexa relação, é importante considerar a complexidade não como ponto a ser evitado, já que as interações humanas são constituídas assim, mas por meio dessa complexidade objetivamos uma crescente compreensão processual.

A fase final consistiu na aplicação do quadro acima para as postagens e interações de cada participante, gerando um resultado qualitativo descritivo dos aspectos relevantes das interações estabelecidas. Leon, Jayashri, Girassol, R. Soares, Rudolf e Chese são os participantes desta pesquisa ${ }^{3}$. Aqui indicamos os principais destaques do que foi construído.

${ }^{3}$ Nomes indicados por escolha dos próprios participantes da pesquisa. 
4. RESULTADOS E DISCUSSÕES

Foram analisadas um total de 37 (trinta e sete) postagens: 26 (vinte e seis) postagens com fotos e 11 (onze) postagens com vídeos. Nestas postagens, encontramos três tipos de imagem: 27 (vinte e sete) postagens com fotos ou vídeos do próprio participante, 08 (oito) postagens de fotos com amigos e/ou família, 02 (duas) imagens com mensagens de ações sociais (essas duas últimas são do Rudolf). As fotos e vídeos do próprio participante são quase a totalidade do que foi encontrado. Essa forma de colocar-se nos parece correlacionada com as marcas do tempo histórico e da concretude de vida, pois o ser jovem tem relação com o momento de vida, mas também com a conjuntura histórica (ABRAMO, 2016). Outras marcas são os processos de identidade que se constroem em relação com o outro, nas vivências de papéis múltiplos que são vistos e reforçados em relação ao outro que lê e interage (CIAMPA, 1987; VYGOTSKY, 1988). Aos múltiplos papéis originam-se identidades que são experienciadas nos cenários sociais (BAUMAN, 2008), inclusive no Instagram, nos sugerem as postagens e as interações, que existem espaços de criação/reforço destas identidades por meio das possibilidades que a plataforma permite criar. Ao verificarmos que, por volta de $70 \%$ das postagens referem-se ao próprio sujeito e as demais ao sujeito com seus amigos e familiares, entenderemos isso como marcas do processo de construção identitária representadas nas ações virtuais, fazendo da rede social um local de construção identitária pela interação mediada por tecnologia (Quadro 2).

Quadro 2: Resumo das ações dos participantes. Fonte: Autoria Própria.

\begin{tabular}{|c|c|c|c|}
\hline \multicolumn{3}{|c|}{ Girassol } \\
\hline $\begin{array}{c}\text { Planejamento e Organização das } \\
\text { Postagens }\end{array}$ & $\begin{array}{c}\text { Propriedades } \\
\text { operacionais }\end{array}$ & Comunicação & Dimensão Afetiva \\
Curtidas /Visualizações e Comentários & Comenta & \\
\hline
\end{tabular}


4 postagens com fotos e 1 vídeo.

Somente imagens sozinha

Média de likes 1812; média de comentários 49,8; maior número de likes/visualizações 4077

Nível de planejamento - 5
Todas as imagens apresentam boas produções, maquiagem, iluminação etc Textos curtos emojis na legenda Nível de propriedades operacionais - 5
Resposta

e/ou curtidas

em todos os comentários

Nível de comunicação $-3$
Muitos comentários

de pessoas

conhecidas, família e amigos. Alguns, porém, aparentam ser de desconhecidos. A interação se restringe a poucas palavras, normalmente um elogio e às curtidas. Nível afetivo - 3

\begin{tabular}{|c|c|c|c|}
\hline \multicolumn{4}{|c|}{ Rudolf } \\
\hline $\begin{array}{l}\text { Planejamento e Organização das } \\
\text { Postagens } \\
\text { Curtidas /Visualizações e Comentários }\end{array}$ & $\begin{array}{l}\text { Propriedades } \\
\text { operacionais }\end{array}$ & Comunicação & Dimensão Afetiva \\
\hline $\begin{array}{l}3 \text { postagens. Apenas } 1 \text { foto com o } \\
\text { que parece ser com a família } \\
\text { Média de likes 60,33; média de } \\
\text { comentários 3,33; maior número de } \\
\text { likes/visualizações } 130 \text { (foto com a } \\
\text { família) } \\
\text { Não possui indícios de planejamento } \\
\text { ou de organização para postagens } \\
\text { Nível de planejamento - } 2\end{array}$ & $\begin{array}{l}\text { A foto com a } \\
\text { família tem nitidez } \\
\text { e as pessoas estão } \\
\text { sorrindo, } 2 \\
\text { postagens com } \\
\text { imagens } \\
\text { comemorativas } \\
\text { liberadas por um } \\
\text { político } \\
\text { Não há legendas } \\
\text { Nível de } \\
\text { propriedades } \\
\text { operacionais - } 3\end{array}$ & $\begin{array}{l}\text { Não há } \\
\text { retorno em } \\
\text { nenhum } \\
\text { comentário, } \\
\text { nem com } \\
\text { palavras e } \\
\text { nem com } \\
\text { curtidas } \\
\text { Nível de } \\
\text { comunicação } \\
\text { - } 1\end{array}$ & $\begin{array}{l}\text { Não foi possível } \\
\text { avaliar essa dimensão } \\
\text { em relação à } \\
\text { interação } \\
\text { Nível afetivo - } 1\end{array}$ \\
\hline \multicolumn{4}{|c|}{ Chese } \\
\hline $\begin{array}{l}\text { Planejamento e Organização das } \\
\text { Postagens } \\
\text { Curtidas /Visualizações e Comentários }\end{array}$ & $\begin{array}{l}\text { Propriedades } \\
\text { operacionais }\end{array}$ & Comunicação & Dimensão Afetiva \\
\hline $\begin{array}{l}1 \text { postagem com foto } \\
62 \text { curtidas e } 4 \text { comentários } \\
\text { Não possui indícios de planejamento } \\
\text { ou de organização para postagens } \\
\text { Nível de planejamento - } 2\end{array}$ & $\begin{array}{l}\text { A foto tem uma } \\
\text { imagem da } \\
\text { participante, } \\
\text { média nitidez e } \\
\text { não está sorrindo } \\
\text { Não há legendas } \\
\text { Nível de } \\
\text { propriedades } \\
\text { operacionais - } 4\end{array}$ & $\begin{array}{l}\text { Há resposta } \\
\text { apenas com } \\
\text { emojis, há } \\
\text { curtidas aos } \\
\text { comentários } \\
\text { Nível de } \\
\text { propriedade } \\
\text { comunicativa } \\
\text { - } 3\end{array}$ & Nível afetivo - 3 \\
\hline
\end{tabular}




\begin{tabular}{|c|c|c|c|}
\hline \multicolumn{4}{|c|}{ Jayashri } \\
\hline $\begin{array}{c}\text { Planejamento e Organização das } \\
\text { Postagens } \\
\text { Curtidas /Visualizações e Comentários }\end{array}$ & $\begin{array}{l}\text { Propriedades } \\
\text { operacionais }\end{array}$ & Comunicação & Dimensão Afetiva \\
\hline $\begin{array}{l}3 \text { postagens com fotos. Destas, } 1 \\
\text { com amigos } \\
\text { Média de likes 245; média de } \\
\text { comentários 44,663; maior número } \\
\text { de likes/visualizações } 269 \\
\text { Possui certos indícios de } \\
\text { planejamento na postagem } \\
\text { Nível de planejamento - } 5\end{array}$ & $\begin{array}{l}\text { As imagens são } \\
\text { evidentemente } \\
\text { elaboradas, com } \\
\text { maquiagem e } \\
\text { relação entre elas, } \\
\text { além de nítidas e } 2 \\
\text { parecem ter sido } \\
\text { feitas } \\
\text { exclusivamente } \\
\text { para isso. } \\
\text { Textos curtos } \\
\text { emojis nas } \\
\text { legendas } \\
\text { Nível de } \\
\text { propriedades } \\
\text { operacionais - } 5\end{array}$ & $\begin{array}{l}\text { Resposta } \\
\text { e/ou curtidas } \\
\text { em todos os } \\
\text { comentários - } \\
5\end{array}$ & $\begin{array}{l}\text { As pessoas que } \\
\text { comentam parecem } \\
\text { ser conhecidas e } \\
\text { também familiares. } \\
\text { Alto retorno e alguma } \\
\text { comunicação } \\
\text { específica. } \\
\text { Nível afetivo - } 5\end{array}$ \\
\hline \multicolumn{4}{|c|}{ Leon } \\
\hline $\begin{array}{c}\text { Planejamento e Organização das } \\
\text { Postagens } \\
\text { Curtidas /Visualizações e Comentários }\end{array}$ & $\begin{array}{l}\text { Propriedades } \\
\text { operacionais }\end{array}$ & Comunicação & Dimensão Afetiva \\
\hline $\begin{array}{l}7 \text { postagens com fotos, } 2 \text { delas com } \\
\text { amigos } \\
\text { Média de likes 51,71; média de } \\
\text { comentários 4,57; maior número de } \\
\text { likes/visualizações } 58 \\
\text { Possui algum indício de } \\
\text { planejamento das postagens } \\
\text { Nível de planejamento - } 4\end{array}$ & $\begin{array}{l}\text { As imagens são } \\
\text { evidentemente } \\
\text { elaboradas, com } \\
\text { alguma certa } \\
\text { relação entre elas, } \\
\text { além de nítidas e } 4 \\
\text { parecem ter sido } \\
\text { feitas } \\
\text { exclusivamente } \\
\text { para postagem. } \\
4 \text { sem legendas, } 2 \\
\text { com emojis, } 1 \text { com } \\
\text { uma frase curtas } \\
\text { Nível de } \\
\text { propriedades } \\
\text { operacionais - } 5\end{array}$ & $\begin{array}{l}\text { Curte a } \\
\text { maioria dos } \\
\text { comentários, } \\
\text { às vezes } \\
\text { responde, } \\
\text { normalmente } \\
\text { com emojis e } \\
\text { frases, } \\
\text { amigos } \\
\text { marcados } \\
\text { Nível de } \\
\text { comunicação } \\
\text { - } 4\end{array}$ & $\begin{array}{l}\text { Comentários são de } \\
\text { amigos ou família, } \\
\text { repetem-se nas } \\
\text { postagens, usam de } \\
\text { certa "implicância" } \\
\text { carinhosa e de gírias } \\
\text { ou falas de memes } \\
\text { Nível afetivo - } 4\end{array}$ \\
\hline \multicolumn{4}{|c|}{ R. Soares } \\
\hline $\begin{array}{c}\text { Planejamento e Organização das } \\
\text { Postagens } \\
\text { Curtidas /Visualizações e Comentários }\end{array}$ & $\begin{array}{l}\text { Propriedades } \\
\text { operacionais }\end{array}$ & Comunicação & Dimensão Afetiva \\
\hline
\end{tabular}


19 postagens, 10 vídeos, 9 fotos. 5 Fotos com amigos

Média de likes 26,33; média de comentários 4,15; maior número de likes/visualizações 124

Possui alto indício de planejamento nas postagens. Algumas, como os vídeos, são feitas exclusivamente para postagem. Nível de planejamento - 5
Todas postagens têm legenda em frases curtas e/ou emojis. Usa trecho de música ou frase inspiradora em 3, algumas postagens possuem hashtags. Nível de propriedades operacionais - 5
Curte a maioria dos comentários, às vezes responde, normalmente com emojis e frases Nível de comunicação $-5$

No Quadro 2 estão resumidas as ações dos participantes, no período da pesquisa: suas escolhas, suas postagens, as interações, as análises feitas a partir dos objetivos definidos, tomando como ponto de apoio o referencial teórico e as próprias postagens ao longo do tempo.

A realidade não é apenas a material, pois o virtual possui uma continuidade percebida. Vemos isso nas formas pelas quais as ações presenciais ou virtuais são híbridas nas interações dos jovens. Ações de um e de outro se sobrepõem e caracterizam, de maneira dialética e indissociável. Verificamos isso, principalmente nas postagens de Girassol, Jayashri, Leon e R. Soares. Isso, porque percebemos que a intencionalidade das postagens e das interações são uma relação das ações nas redes e na materialidade, não podendo ser separadas. Em suas postagens, são representadas ou aludidas ações que começam ou terminam no material ou no virtual, reforçando a não separação entre essas realidades que compõem a unidade da vida, na multiplicidade de papéis e realidades (LÉVY, 1996).

Quanto aos likes, visualizações e comentários, existem estudos sobre padrões que buscam indicar ações para o aumento de likes e visualizações para fins de monetização ou, pelo menos, para a fama virtual (ALMEIDA, 2016). Ainda assim, se considerarmos likes e visualizações como uma das formas de perceber o alcance de 
uma postagem, encontramos o vídeo de Girassol, com 4077, conforme consta da planilha e outras postagens com média de 20 likes. Porém, parece-nos que estes números podem representar alcances, mas não mostram a realidade das interações. Eles parecem mais relacionarem-se com os aspectos de planejamento e organização das postagens e ações, pois as que possuem evidências de terem recebido maior atenção dos participantes - tais como a preocupação com os aspectos técnicos das postagens: foto nítida, paisagens bonitas, maquiagem, organização do cenário etc foram mais vistas ou curtidas.

Porém, em relação aos comentários, duas coisas chamaram a atenção quanto ao nível de comunicação: as postagens com marcação de amigos possuíam mais retorno, senão em likes, pelo menos em comentários. Como exemplo, as postagens de Leon e Jayashri que possuem fotos marcadas com amigos, em comparação com outras postagens sem essas marcações. Uma outra questão é que quando são dadas respostas aos comentários das pessoas nas postagens, a tendência é reforçar novos comentários, parece-nos haver uma relação quanto ao que é mais comumente visto nas conversas materializadas na presencialidade: falamos, queremos ser ouvidos e respondemos ao que ouvimos, em um ciclo que permite a análise dos pontos do diálogo. Mesmo que seja uma "conversa" entre mais de duas pessoas, quando existe o retorno ao que foi comentado, aproxima-se mais de aspectos da interação. Isso ocorreu nas ações do Instagram verificadas, por exemplo, nas postagens de Jayashri e R. Soares - como exemplo de comunicação e da de Rudolf - como exemplo de não retorno.

A tentativa de compreensão nas comunicações e, com isso, a busca pela interação, parece levar ao uso de emojis, gírias e curtidas dos comentários em quase todos os participantes, com alguma exceção de Rudolf. O fato é que é a própria complexidade das interações que acaba criando a necessidade do uso de mais do que a escrita. A imensidão dos horizontes extraverbais que existem nas conversas a partir 
de imagens postadas pelos jovens participantes leva à necessidade de artifícios para expressarem parte de universo de significações, a necessidade de compreensão do universo subjetivo do falante inclui memes, imagens, emojis assim como o compartilhamento de uma realidade comum (VOLOSHINOV \& BAKHTIN, 1976). Foram muitos os momentos nos quais isso foi mais evidente: legendas com variados emojis ou hashtag de todos que incluem legendas nas postagens, diálogo puramente compostos por emojis de Jayashri, gírias e "memes", como em diálogos de Leon ou comentários nas postagens de Girassol.

A interação no Instagram somente é possível a partir das disponibilidades do próprio Instagram, ou seja, postagens de foto ou vídeo, comentários, lives etc. Além disso, são as definições algorítmicas que indicam ou escondem perfis com base em curtidas anteriores e na impulsão de conteúdos para fins financeiros, tudo isso interfere na experiência da interação. Porém, quanto à intensidade dela, não parece ser, em si, a tecnologia a maior interferência. Continua sendo necessária a compreensão das características concretas dos modos de vida, das marcas da história pessoal e social e do universo extraverbal, para que a interação aconteça com intensidade.

\section{CONSIDERAÇÕES FINAIS}

As interações são sempre fruto da relação dialética entre o social e o individual e somente poderão ser compreendidas na complexidade dessa relação. Buscamos o estranhamento das interações nas redes sociais, ao mesmo tempo em que indicamos tais movimentos como possibilidade de interação contemporânea, tão válida quanto as tradicionais e entendemos que poderão ser delineados aspectos comuns, graus de comparatividade, situações diversas nas interações, de forma que mostrem cartografias, topografias, relevos e disponibilidades, que possam ser referenciadas na aplicação desta escala e em trabalhos futuros com objetivos complementares. 
As interações virtuais não significam descontinuidade da vida material, são interações de continuidade com outras formas e experiências da vida. É importante não isolar uma relação da outra, na busca por compreender o processo de interação. Likes e curtidas relacionam-se com o alcance das postagens, razão pela qual, estão em paralelo com padrões próprios das redes sociais, algoritmos e com a qualidade técnica que envolve uma postagem, seja ela imagem ou vídeo. Postagens com marcação com nome dos amigos tiveram mais retorno e comentários respondidos, geraram novas respostas em uma tendência de maior comunicação. Quanto aos emojis, memes e outras expressões próprias das escritas virtuais, entendemos que a complexidade das interações, em especial sem a possibilidade dos recursos da presencialidade, acaba criando a necessidade da busca de meios de expressão e compreensão do universo subjetivo dos falantes e, com isso, para a interação.

Ficam questionamentos, para fins de aprofundamento, se o valor encontrado na necessidade de entendimento das formas concretas de vida da juventude e do universo extraverbal das interações, como pontos muito importante para as interações mediadas por tecnologias, também podem ser encontrados como importantes para as ações educacionais interativas mediadas por tecnologias.

\section{AgRADECIMENTOS}

Agradecemos ao Leon, à Jayashri, à Girassol, ao R. Soares ao Rudolf e à Chese por terem altruisticamente compartilhado conosco um pouco de suas vidas, demonstradas em suas postagens.

Agradecemos à Universidade Federal do Rio de Janeiro (UFRJ), ao Instituto Federal do Espírito Santo (IFES) e à Universidade de Coimbra (UC), pelo apoio à pesquisa realizada. O presente trabalho foi realizado com apoio da Coordenação de Aperfeiçoamento de Pessoal de Nível Superior - Brasil (CAPES) - Código de Financiamento 001. 


\section{REFERÊNCIAS}

ABRAMO, Helena Wendel. Identidades juvenis: estudo, trabalho e conjugalidade em trajetórias reversíveis. In: Novaes, Regina et al. (orgs.). Agenda Juventude Brasil: leituras sobre uma década de mudanças. Rio de Janeiro: Unirio, 2016, pp. 19-61. Disponível em: https://bibliotecadigital.mdh.gov.br/jspui/handle/192/133. Acesso em: 18 maio 2020.

ALMEIDA, Mariana Nogueira Amaral de. Jornalismo online: o segredo das visualizações. Dissertação de Mestrado (Ciências da Comunicação). 2016. Faculdade de Ciências Sociais e Humanas. Universidade Nova de Lisboa, 2016. Disponível em: http://hdl.handle.net/10362/19740. Acesso em: 18 maio 2020.

ANDERSON, Terry. Getting the Mix Right Again: An Updated and Theoretical Rational for Interaction. The International Review of Research in Open and Distributed Learning, v. 4, n. 2, 1 Oct. 2003. Disponível em: https://doi.org/10.19173/irrodl.v4i2.149. Acesso em: 10 ago. 2020.

ARGYLE, Michael. A interação social: relações interpessoais e comportamento social. Rio de Janeiro: Zahar, 1976

BAUER, Martin. W. Análise de Conteúdo Clássica: uma revisão. In: BAUER, Martin. W. GASKELL, George. Pesquisa Qualitativa com Texto, Imagem e Som: um Manual Prático. Petrópolis: Editora Vozes, 2002.

BAUMAN, Zygmund. A sociedade individualizada: vidas contadas e histórias vividas. Rio de Janeiro: Jorge Zahar, 2008.

BAUMAN, Zygmund. Sobre educação e juventude: conversas com Riccardo Mazzeo/Zygmunt Bauman. Rio de Janeiro: Jorge Zahar, 2013.

BENJAMIN, Walter. A vida dos estudantes. In BENJAMIN, Walter. Documentos de cultura, documentos de barbárie: escritos escolhidos. Seleção e apresentação Willi Bolle, São Paulo: Editora Cultrix; Editora da Universidade de São Paulo, 1986.

BRASIL. Lei № 12.852 de 5 de agosto de 2013. Institui o Estatuto da Juventude. Disponível em: http://www.planalto.gov.br/ccivil_03/_ato20112014/2013/lei/l12852.htm. Acesso em 11 jun. 2020.

CARDOSO, Beatriz. Instagram Stories faz 2 anos; veja a evolução da ferramenta. Techtudo. Disponível em: https://www.techtudo.com.br/noticias/2018/08/instagramstories-faz-2-anos-veja-a-evolucao-da-ferramenta.ghtml. Acesso em: 20 jul. 2020.

COSTA DO VALE, Maria do Socorro; COSTA, Denise Coutinho; ALVES JR, Nilton. Internet: Histórico, Evolução e Gestão. CBPF-NT-005/01, 2001. Disponível em: https://mesonpi.cat.cbpf.br/naj/InternetHEG5C.pdf. Acesso em: 20 jul. 2020. 
CETIC.BR. Centro Regional de Estudos para o Desenvolvimento da Sociedade da Informação. Pesquisa sobre o Uso das Tecnologias de Informação e Comunicação nos domicilios brasileiros - TIC Domicílios 2005. Disponível em: http://data.cetic.br/cetic/explore?idPesquisa=TIC_DOM\&idUnidadeAnalise=Domicilio s\&ano=2005. Acesso em: 03 ago. 2020.

CETIC.BR. Centro Regional de Estudos para o Desenvolvimento da Sociedade da Informação. Pesquisa sobre o Uso das Tecnologias de Informação e Comunicação nos domicilios brasileiros - TIC Domicílios 2018. Disponível em: http://data.cetic.br/cetic/explore?idPesquisa=TIC_DOM\&idUnidadeAnalise=Usuarios \&ano=2018. Acesso em: 03 ago. 2020.

JUNIOR, Hamilcar Silveira Dantas. A Juventude Entre a História e a Memória: a rebeldia como tradição inventada e espetacular. Ponta de Lança: Revista Eletrônica de História, Memória \& Cultura, v. 2, n. 2, p. 63-82, 31 out. 2007.

ESTEBAN, María Paz Sandín. Pesquisa qualitativa em educação: fundamentos e tradições. Porto Alegre: Artmed, 2010.

G1 SÃO PAULO. Entenda a curta história do Instagram, comprado pelo Facebook. 10/04/2012 07h29-Atualizado em 16/04/2012 19h33. Disponível em: http://g1.globo.com/tecnologia/noticia/2012/04/entenda-curta-historia-doinstagram-comprado-pelo-facebook.html. Acesso em 20 jul. 2020.

HARVEY, David. Política anticapitalista em tempos de COVID-19. In: DAVIS, Mike. et.al. (orgs.). Coronavírus e a luta de classes. Brasil: Terra sem Amos, 2020.

HILLMAN, Daniel. C. A.; WILLIS, Deborah. J.; GUNAWARDENA, Charlotte. N. Learnerinterface interaction in distance education: An extension of contemporary models and strategies for practitioners, American Journal of Distance Education, v. 8 n. 2, p. 30-42, 1994. Disponível em: DOI: 10.1080/08923649409526853. Acesso em 13 jun. 2020.

HORKHEIMER, Max. Teoria Tradicional e Teoria Crítica (publicado pela primeira vez em 1937). In: HORKHEIMER, Max e ADORNO, Theodor. Textos Escolhidos. São Paulo, Abril Cultural, 1983.

KOZINETS, Robert. V. Netnografia: Realizando pesquisa etnográfica online. Porto Alegre: Penso, 2014. 203p.

LEMOS, Andre. L. M. Anjos interativos e retribalização do mundo: Sobre interatividade e interfaces digitais. Tendências XXI, Lisboa, 1997. Disponível em: https://www.facom.ufba.br/ciberpesquisa/lemos/interativo.pdf. Acesso em: 07 março 2020.

LÉVY, Pierre. O que é virtual? Trad. Paulo Neves. São Paulo: Ed. 34, 1996. 157p. 
MARCUSE, Herbert. Eros e civilização: uma Interpretação Filosófica do Pensamento de Freud. 6 ed. Rio de Janeiro: Zahar, 1975.

MCINTYRE, Karen. The Evolution of Social Media from 1969 to 2013: A Change in Competition and a Trend Toward Complementary, Niche Sites. The Journal of Social Media in Society, v.3 n. 2, Fall 2014. Disponível em: https://thejsms.org/index.php/TSMRI/article/view/89. Acesso em: 07 março 2020

MOORE, Michael. Teoria da Distância Transacional. In: KEEGAN, Desmond. Theoretical Principles of Distance Education. 1993. [Tradução de Wilson de Azevedo, revisão de tradução de José Manuel da Silva] (v.1, ago). 2002. Revista Brasileira de Aprendizagem Aberta $e$ a Distância. Disponível em: http://www.abed.org.br/revistacientifica/Revista_PDF_Doc/2002_Teoria_Distancia_T ransacional_Michael_Moore.pdf. Acesso em: 18 ago. 2020.

MOORE, Michael; KEARSLEY, Greg. A educação a distância: uma visão integrada. Trad. Roberto Galman. São Paulo: Thomson Learning, 2007.

NOVAES, Regina. Juventude, religiosidade, territórios e redes: reflexões sobre resultados de pesquisas. In: PINHEIRO, Diógenes et al (Org.). Agenda Juventude Brasil: leituras sobre uma década de mudanças. Rio de Janeiro: Unirio, 2016. 186 p. Disponível em: http://bibjuventude.ibict.br/jspui/handle/192/133. Acesso em: 18 out. 2020.

OLIVEIRA, Marta Kohl de. Vygotsky e o processo de formação de conceitos. In: LA TAILLE, Yves Joel Jean Marie Rodolphe de; OLIVEIRA, Marta Kohl de; PINTO, Heloysa Dantas de Souza. Piaget, Vygotsky, Wallon: teorias psicogenéticas em discussão. São Paulo: Summus, 1992.

PERNISA JÚNIOR, Carlos. Jornalismo Transmidiático ou Multimídia? Curitiba, v. 10, n. 2, jul./dez. 2010. Disponível em: https://seer.utp.br/index.php/i/article/view/99. Acesso em: 15 março 2020.

PORTO, Cristiane; OLIVEIRA, Kaio Eduardo; CHAGAS, Alexandre. Whatsapp e educação: entre mensagens, imagens e sons. Salvador: EDUFBA. Disponível em: https://doi.org/10.7476/9788523220204. Acesso em: 15 março 2020.

PRIMO, Alex Fernando Teixeira. Interação mediada por computador: a comunicação e a educação a distância segundo uma perspectiva sistêmico-relacional. Tese (Doutorado) - Universidade Federal do Rio Grande do Sul, Porto Alegre, 2003. Disponível em: https://lume.ufrgs.br/handle/10183/6959. Acesso em: 9 fev. 2020.

RECUERO, Raquel. Redes sociais na internet. Porto Alegre: Sulina, 2009.

SIMS, Rod. Interactivity: A forgotten art?. Computers in Human Behavior. v. 13 n. 2, p.157-180, May 1997. Disponível em: https://doi.org/10.1016/S0747-5632(97)000046. Acesso em: 19 jan. 2020. 
SPOSITO, Marilia Pontes (coord.). Juventude e Escolarização (1980-1998). Brasília: MEC/Inep/Comped, 2002. p. 221

VYGOTSKY, L. S. A formação social da mente. 2.ed. Brasileira. Martins Fontes, 1988.

VOLOSHINOV, Valentin Nikolaevich; BAKHTIN, Mikhail. Discurso na vida e discurso na arte: sobre poética sociológica. Feudism, Nova lorque, 1976, p. 1-25. [1926]. Disponível em: https://docente.ifrn.edu.br/paulomartins/linguistica/discurso-na-vidae-discurso-na-arte-de-bakhtin-e-voloshinov. Acesso em: 09 março 2020.

VYGOTSKY, Lev Semyonovic. (1896-1934). A construção do pensamento e da linguagem. São Paulo: Martins Fontes, 2001. 